\title{
Arbetslöshetens konsekvenser bland ungdomar
}

- en översikt

\section{ANNE HAMMARSTRÖM}

Arbetslöshet, särskilt bland ungdomar, utgör ett av de allvarligaste problemen i dagens samhälle. Artikeln ger en översikt av den forskning som är gjord inom området. Säväl selektions- som expostionseffekter kan påvisas. Arbetslöshet visar sig vara en riskfaktor för såväl kroppslig sompsykisk ohälsa, för försämrade hälsovanor samt för sociala konsekvenser. Forskningen behöver nu inriktas mot mer kvalitativ metodik i syfte att söka efter djupare mekanismer, medierande faktorer och förklaringsmodeller till det ojämt fördelade hälsotillståndet $i$ samhället, där arbetslöshet har visat sig vara en viktig faktor.

Arbetslöshet, särskilt bland ungdomar, är ett av de allra allvarligaste problemen i dagens samhälle. Västvärldens arbetslöshet har ökat påtagligt under det senaste decenniet. I OECD-länderna var ungdomsarbetslösheten i åldrarna 16 till 24 år cirka fem procent 1973. Under tioårsperioden fram

Anne Hammarström, universitetslektor och docent i folkhälsovetenskap vid institutionen för allmänmedicin, Umeå universitet. till 1983 har den siffran mer än tredubblats. Under tiden därefter har den legat på en fortsatt hög nivå (OECD 1994).

Arbetslöshetens hälsoeffekter har blivit ett allt viktigare område för forskning. Det relativa antalet artiklar som har indexerats $i$ Medlines medicinska databas har mer än fördubblats mellan 1970-talet och 1980-talet (Janlert 1991). Trots det utgör fortfarande det totala antalet artiklar, som handlar om arbetslöshet, mindre än en halv promille 




Socialvetenskaplig tidskrift $\mathrm{nr}$ 1-2 96 
av alla artiklar i databasen. Flertalet av dessa artiklar handlar om vuxenarbetslöshet, vilket betyder att forskningen om ungdomsarbetslöshet alltjämt är mycket eftersatt.

\section{Teoretisk bakgrund}

Relativt få studier inom området är baserad på teoretiska utgånspunkter. De teoretiska ansatser som oftast har använts kan klassificeras som ekonomisk deprivationsteori, stressrelaterade modeller samt ett antal mer specifika psykologiska och sociologiska teorier. Ett avsevärt antal studier använder adhoc modeller, dvs teorier som konstrueras under själva analysprocessen när data redan är insamlade, i syfte att finna rimliga förklaringar till resultaten.

Deprivationsteorin betonar att arbetslöshet är skadligt för människor på grund av de ekonomiska konsekvenser den medför. Denna teori var förhärskande under 30-talet. Samhällets viktigaste insatser mot arbetslöshet blev då en typ av arbetsmarknadspolitisk åtgärd (AK-arbeten) som gav viss ekonomisk ersättning. Men ohälsoproblemen kvarstod och teorin framstod som otillräcklig. Till den ekonomiska teorin kan också räknas de multivariata modeller som använts av Brenner (1983) för att belysa sambanden mellan ekonomisk utveckling och hälsotillstånd. Sammanfattningsvis visar hans forskning att en ökad arbetslöshet $i$ USA samvarierar med ökad dödlighet i bland annat kardiovaskulära sjukdomar, självmord, mord och ökad spädbarnsdödlighet. Brenners modell säger dock inget om etiologin. Den säger inte heller något om vad som händer med de arbetslösa, bara vad som händer i samhället som helhet.
Enligt stressteorin fungerar arbetslöshet och osäkerhet om ens framtida arbetssituation som stressorer (Kagan, Levi 1975). Denna teori har fătt stöd i tidigare studier om arbetslöshet bland vuxna, både bland kvinnor (Arnetz o.a. 1987) och män (Cobb, Kasl 1977). En utveckling av stressmodellen inom ramen för stress i förvärvsarbete pekar mot en synergistisk effekt av höga arbetskrav och lågt beslutsutrymme (Karasek, Theorell 1990). För en given kravnivå ökar stressnivån om beslutsutrymmet minskar. Teorin borde kunna gälla vid arbetslöshet, som då förmodas innebära en passiv verksamhet med låga krav och lågt beslutsutrymme.

De socialpsykologiska modellerna tar sin utgångspunkt i ett antal mer eller mindre empiriskt prövade teorier.

Enligt kritisk psykologi kan vi inte förstå en människas situation som arbetslös om vi inte vet vilket slags arbete som hon eller han hade före arbetslösheten. Vad arbetet kan betyda för en människa, utöver de rent ekonomiska aspekterna, har analyserats av den engelska forskaren Marie Jahoda (1979). Arbetet medför enligt hennes så kallade behovsteori att även andra behov än de rent ekonomiska uppfylls. Arbetet leder sålunda till:

- tidsstruktur på dagen

- sociala kontakter

- arbete för mål som en människa inte ensam kan nå

- personlig status och identitet

- ökad aktivitet

En engelsk studie (Miles 1983) visade att människor som i stor utsträckning kunde fylla dessa behov, trots att de var arbetslösa, hade färre psykiska problem än de som inte 
kunde ersätta arbetsbehoven. Dessa behov uppfylls naturligtvis inte genom alla jobb, utan arbetets betydelse varierar beroende på arbetets art, innehåll samt olika arbetsmiljöförhållanden.

Människor som vill arbeta men inte får något arbete saknar i väsentlig grad kontroll över sin situation. Denna brist på kontroll kan medföra passivitet, negativ självuppfattning, dåligt självförtroende samt depression enligt teorin om inlärd hjälplöshet (Seligman 1975, Abramson o.a. 1978). Andra förhållanden såsom klass- och könstillhörighet har även i unga år stor betydelse för såväl hur starkt bristen på kontroll upplevs, som vilka hälsokonsekvenser den medför.

Ett annat kontrollbegrepp, intern respektive extern kontroll (locus of control), har ofta använts i bland annat australiensk ungdomsarbetslöshetsforskning (Tiggemann, Winefield 1984, Feather 1983). Med intern kontroll avses att den arbetslöse ser sig själv som delaktig i att ha blivit arbetslös. Med extern kontroll avses att den arbetslöse anser att arbetslösheten helt och hållet beror på yttre faktorer. De som ser sig själva som delaktiga i sin arbetslöshet förväntas må bättre, eftersom de förmodas få bättre kontroll över sin situation, jämfört med dem som förlägger orsaken på samhället.

Kvinnor har ofta saknats i såväl teorier som forskning om arbetslöshet. Olika forskare, inklusive några av de fåtaliga kvinnliga forskarna inom området, hävdar att arbetslöshet inte blir lika destruktiv för kvinnor som för män eftersom kvinnor då kan kompensera för arbetslöshetens negativa inverkan genom att återgå till sin hustruroll. Tanken är att hushållsarbetet kan tjäna som en tillfredställande ersättning för lönearbete
(Jahoda 1982, Ovesen 1978). Studier som omfattar kvinnor visar dock att kvinnor drabbas hårt av arbetslöshet (Davies, Essevold 1988), och effekterna är minst lika stora som bland män (Iversen L o.a. 1987) under förutsättning att samma kriterier används för att definera arbetslöshet (Leeflang o.a. 1992). Detta tyder på att arbetslöshet är lika allvarligt för kvinnor som för män.

Teorierna som har använts $i$ arbetslöshetsforskning kan granskas ur ett genusperspektiv. Ett första led i denna teori är att synliggöra kvinnors villkor, vilket i fallet arbetslöshetforskning bland annat innebär att även kvinnor inkluderas i studierna samt att könsskillnader särredovisas. Nästa steg är att synliggöra vilken betydelse som relationerna mellan kvinnor och män har för deras upplevelser och erfarenheter av arbetslöshet. Dessa relationer betraktas som en socialt föränderlig konstruktion som inte är av naturen given. De innebär ett icke urskiljbart samspel mellan biologiskt och socialt/ kulturellt konstruerat kön. Strukturellt sett karakteriseras denna relation mellan könen av mannens överordning, tolkningsföreträde och makt. Denna överordnade position bestäms inte enbart av könstillhörighet, utan andra förhållanden såsom social- och etnisk bakgrund, religion och ålder har också avgörande betydelse för maktfördelningen i samhället (Berggren A stencil 1995).

\section{Selektion eller exposition}

En av huvudfrågorna inom arbetslöshetsforskning är kausalitetsfrågan bakom sambanden mellan arbetslöshet och ohälsa. Är sambanden utryck för exposition eller selektion? Är det människor som redan mår 
dåligt som blir arbetslösa eller är det arbetslöshet som orsakar dålig hälsa? Kanhända är det människor med sämst hälsa som blir arbetslösa, vilket i sin tur kan förvärra situationen.

Frågan om selektion/exposition är relevant för alla slags individuella effekter av arbetslöshet, men har huvudsakligen diskuterats i samband med alkoholmissbruk. Men flera studier inom området har varit av tvärsnittskaraktär, vilket gjort det svårt att studera sambandens riktning.

Teorierna och hypoteserna inom området kan betraktas som ett sökande efter en universalteori, giltig en gång för alla inom arbetslöshetsforskningen. I postmoderna analyser skiftar intresset från en universalteori till ett accepterande av teoretisk instabilitet (Harding 1986), med olika teorier som är giltiga i olika sociala, kulturella och historiska sammanhang. Ett sådant teoretiskt angreppssätt borde vara ett riktigare sätt att analysera frågan om selektion eller exposition, vilket illustreras av en longitudinell studie om ungdomsarbetslöshetens (Hammarström 1995).

I åldersgruppen 16 till 18 år kan ingen selektion till arbetslöshet påvisas. Det kan bero på att det fanns relativt gott om åtgärder för dessa åldersgrupper samt att de fördelades relativt slumpartat mellan ungdomarna. Mellan 18 och 21 års ålder minskar tillgången på åtgärder, vilket medför att de socialt mest missgynnade ungdomarna drabbas i högst utsträckning av arbetslöshet.

Intresset för frågor om selektion och exposition påverkas av konjukturerna i samhället. I tider av högkonjunktur är intresset mest fokuserat på selektion och om det är människor som redan har sämst hälsa och välfärd som blir arbetslösa. I tider av lågkonjunktur då fler människor är arbetslösa ändras intressefokus till exposition, dvs om arbetslöshet orsakar dålig hälsa.

\section{Effekter på samhälle-grupp-individ}

Arbetslöshetens effekter har ofta enbart studerats i ett individuellt perspektiv, dvs konsekvenserna för den enskilda arbetslösa människan har analyserats. Men arbetslöshet kan aldrig drabba en enskild, utan att detta får effekter för människorna runt omkring. Att även samhället som helhet påverkas av enskilda individers arbetslöshet, har visats i en amerikansk studie, där olika data har samlats under en lång period för att därefter jämföras med arbetslöshetsnivåerna under samma period (Brenner 1980). Härvid får man data på en så kallade aggregerade nivå. Det visar sig då att en procents ökad ungdomsarbetslöshet i USA bland annat innebär en ökning av grova våldtäkter och mord med mellan 10 och 20 procent. En av nackdelarna med denna typ av studier är att det inte är möjligt att veta om det exempelvis är de arbetslösa själva som utför brotten. Men en fördel med aggregerade data är att de kan synliggöra sociala konsekvenser av arbetslöshet, som ofta förblir dolda i individuella studier. Våld mot kvinnor i form av bland annat våldtäkter synliggörs knappast med de frågeställningar och metoder som den traditionella forskningen använder (Russel 1986). I svenska studier har det påvisats att övertidsuttaget ökar i samhället parallellt med arbetslösheten (Starrin o.a.1985). Detta kan vid ett första ögonkast 
te sig paradoxalt, men det förklaras av att arbetsgivaren inte vill eller vågar satsa på nyanställningar vid en lågkonjunktur, utan istället används många gånger ordinarie personal till bristningsgränsen. Att detta kan få effekter för de övertidsarbetande i form av ökad sjuklighet och ökad risk för arbetsskador ter sig uppenbart. Ökad arbetslöshet i samhället riskerar således att medföra ökad ohälsa för såväl de arbetslösa själva som för dem som får behålla sina jobb.

När en människa blir arbetslös, påverkar det inte bara henne själv utan också hennes familj och andra närstående. Ytterst få studier har emellertid belyst frågan vilka effekterna blir för de närstående (Hammarström 1994). Några studier visar ökad risk för barnmisshandel när pappor blir arbetslösa (Rosenthal 1988). Det finns generellt sett ytterst lite arbetslöshetsforskning från tredje världen. Men en indisk studie visar att när män blir arbetslösa ökar risken för att de ska bränna sina fruar till döds, så kallad hustrubränning (Gupta, Srivastava 1987). Bortsett från denna studie har eventuella samband mellan mannens arbetslöshet och kvinnomisshandel inte studerats. Däremot har det visats att kvinnor vars män är arbetslösa upplever ökad stress samt har ökad förekomst av hjärtinfarkt (Penkower o.a. 1988, Moser o.a. 1986).

Arbetslösa ungdomar tillbringar mer tid $i$ hemmet och samtidigt ökar spänningarna $i$ familjen (Roberts o.a. 1982). Det kan innebära många problem för de unga att tvingas bo kvar i föräldrahemmet längre än vad de egentligen själva önskar. Föräldrarna kan av naturliga skäl ha svårt att ge det emotionella och materiella stöd som de unga arbetslösa behöver. En annan försummad aspekt på fa- miljerelationerna är vilken effekt ungdomsarbetslöshet har på föräldrarnas hälsa. Förutom försämrad nattsömn som följd av de ungas förändrade dygnsrytm kan föräldrarnas hälsa försämras av tilltagande ekonomiska bekymmer och av oro för barnens framtid.

\section{Arbetslöshetens effekter på individuell nivå}

Merparten av forskningen har fokuserat individuella konsekvenser. Arbetslöshetens effekter kan klassificeras i följande kategorier:

- hälsovanor

- hälsoeffekter (såsom, kroppsliga besvär, psykiska besvär, sjukvårdsutnyttjande, dödlighet)

- sociala konsekvenser

Ungdomar är överlag oftast friska och motståndskraftiga. Mindre än var tionde ungdom har någon kronisk kroppslig sjukdom eller handikapp (Eiser 1985), medan psykisk ohälsa bedöms förekomma bland mindre än var femte ungdom (Rutter, Sandberg 1987). Tack vare ungdomars goda hälsosituation kan hälsoeffekterna av arbetslöshet förväntas bli mindre uttalade jämfört med bland vuxna. Det ska förmodligen mycket till innan några tydliga hälsoförändringar kan ses bland ungdomar. Däremot kan vi förmoda att många vanor grundläggs under ungdomsåren som på sikt kan få stor betydelse för hälsan, exempelvis tobaks-, alkohol-, narkotika-, vissa mat- och idrottsvanor. Sannolikt får arbetslöshet bland ungdomar i första hand betydelse för hälsovanor, eftersom dessa lättare påverkas av påfrestningar än kroppsliga hälsa. 


\section{Påverkas hälsovanor av arbetslöshet?}

Det finns jämförelsevis få studier som belyser sambanden mellan rökvanor och arbetslöshet, och nästan ingen av dessa studier omfattar ungdomar. Det finns några få tvärsnittsstudier inom området som ger olika resultat. En del studier har påvisat samband mellan cigarettrökning och arbetslöshet men de som blev arbetslösa rökte mycket redan innan de förlorade sina jobb (Morris o.a. 1992). I några undersökningar hittas inga samband mellan tobakskonsumtion och arbetslöshet (Winefield o.a. 1987), medan andra studier påvisar samband (Waldron, Lye 1989).

Det är rimligt att anta att ungdomars tobaksvanor påverkas mer av arbetslöshet än vuxnas, eftersom många hälsovanor tycks grundläggas i tidig ålder. Ett exempel på det är att nästan alla som röker i vuxen ålder har börjat röka innan de fyllt 20 år (Preventing tobacco use 1994).

Arbetslöshet förefaller att vara en riskfaktor för att börja och för att öka cigarettrökning i unga år. Om hänsyn tas till andra förhållanden som också har betydelse för rökvanor, blir risken dubbelt så stor bland arbetslösa 21-åriga kvinnor att vara rökare jämfört med icke arbetslösa kvinnor (Hammarström, Janlert 1994). Motsvarande risktal bland män är något mindre. Övriga hälsovanor förändras inte särskilt mycket vid arbetslöshet. Några undantag är saltning på mat, sovtimmar samt preventivmedelsanvändning. Ju längre arbetslösheten varar ju mer stiger männens sexuella risktagande, definierat som oskyddat samlag utan önskan att få barn (Hammarström 1995).
I forskningsöversikter om sambanden mellan arbetslöshet och alkohol (Forcier 1988) konstateras att det saknas bra studier inom området. Alltför många av undersökningarna är tvärsnittsstudier, vilket omöjliggör analyser av sambandens riktning. Även longitudinella studier inom området är bristfälliga eftersom de sällan studerar människors alkoholvanor innan de blev arbetslösa och eftersom bortfallet med åren blir betydande (Janlert, Hammarström 1992). Det är rimligt att anta att bortfallet har högre alkoholkonsumtion jämfört med deltagarna.

Tabell 1 summerar artiklarna inom området under de senaste decennierna.

Många av studierna har påtagliga metodologiska brister. En del var inte primärt designade för att studera alkoholkonsumtion, medan andra har avsevärda bortfall som kan ogiltiggöra resultaten, eftersom bortfallet tenderar att ha högst alkoholkonsumtion. Andra studier är tvärsnittsstudier där ökad alkoholkonsumtion lika gärna kan vara en orsak till, som en följd av arbetslöshet.

En longitudinell studie påbörjades i skolan, innan någon var arbetslös, och bortfallet blev försumbart. Ungdomar med hög alkoholkonsumtion hade högre risk än andra att bli arbetslösa. Men arbetslöshet i sig medförde också risk för ökat alkoholintag, särskilt bland unga män (Janlert, Hammarström 1992). Kvinnor, men inte män, som fick barn minskade påtagligt sin alkoholkonsumtion. I intervjuer framkom tänkbara förklaringar till varför arbetslöshet kan tänkas medföra ökad alkoholkonsumtion, såsom psykiska påfrestningar, stress samt ökad tillgång till tid. Dålig ekonomi å andra sidan kan hindra arbetslösa från att dricka alkohol (Hammarström 1995).

Missbruk av cannabis och andra illegala 


\section{Tabell 1}

Sammanfattning av artiklar om ungdomsarbetslöshet och alkoholkonsumtion 1978-1995

\begin{tabular}{|c|c|c|c|c|}
\hline Författare & Publ.år & Antal* & Design** & Population \\
\hline $\begin{array}{l}\text { Layne \& } \\
\text { Whitehead }\end{array}$ & 1985 & {$[24 / 3406]$} & $L$ & $\begin{array}{l}\text { Män iåldrarna 15-29 } \\
\text { år }\end{array}$ \\
\hline Kandel et al. & 1986 & {$[1004]$} & $\mathrm{T}$ & $\begin{array}{l}\text { Slumpmässigt urval } \\
\text { elever 15-16 åri } \\
\text { allmänna skolori New } \\
\text { York 1971, uppföljda } \\
\text { |980-81 }\end{array}$ \\
\hline
\end{tabular}

Peck \& Plant $\quad 1986 \quad 83 / 728 \quad \mathrm{~L}$

1036 eleveri $15-16$ årsåldern 1979/80, uppföljning 1983

Resultat

Störst andel storkonsumenter återfinns bland arbetslösa

Alkohol predicerar ökat antal arbetslöshetsperioder bland både kvinnor och män.Variansen förklaras endast till I procent.

Inget signifikant samband mellan arbetslöshet och alkoholkonsumtion men ett svagt samband med narkotikamissbruk

Winefield et al $1987 \quad 78 / 74$ I L

Urval av universitetsstuderande. Svarsfrekvens 24 procent

Ingen säker effekt av arbetslöshet på drogbruk, cigarettrökning eller hälsa

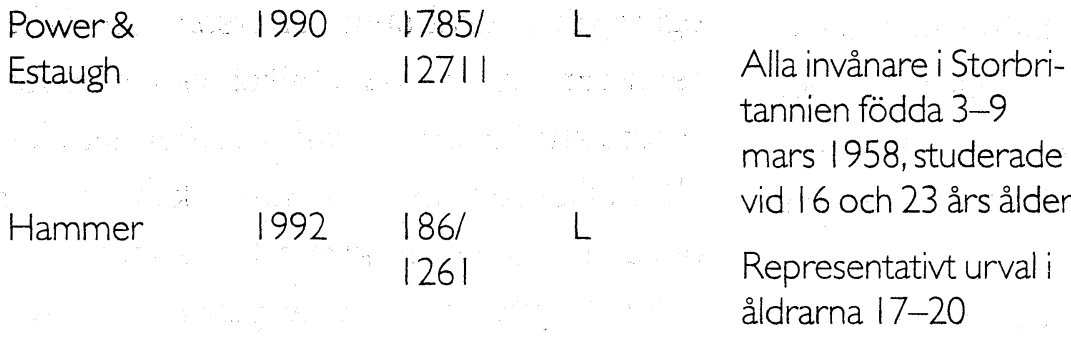

Högre risk för högkonsumtion bland dem som varit arbetslösa $i>6$ månader (OR I,38)

Minskad alkoholkonsumtion i en högkonsumtionsgrupp vid arbetslöshet

$\begin{array}{llll}\text { Janlert \& } & 1992 & 493 / 567 \quad \mathrm{~L}\end{array}$

Kohort avgångsklasser i Män: positiv korr. mellan Hammarström åk 9. Femårsuppföljning

arbetslöshet och alkoholförändring. Kvinnor: negativ korr., som blir positiv efter kontroll för moderskap.

* Antal arbetslösa/antal ickearbetslösa [Siffrorna inom parentes är uppskattade från andra uppgivna data.]

** $T=$ tvärsnittsstudie, $L \approx$ longitudinell

droger har analyserats i några studier, som påvisar att arbetslöshet medför ökad risk för narkotikamissbruk bland såväl unga kvinnor som män (Hammarström 1994, Hammer 1991).

\section{Arbetslöshetens hälsoeffekter}

Eftersom ungdomar utgör en frisk del av populationen är självrapporterade besvär förmodligen en bättre indikator på sjukdoms- 
tillstånd jämfört med kliniska eller biokemiska undersökningar.

Endast ett fåtal studier har fokuserat kroppslig hälsa, vilket framgår av tabell 2 , där resultaten sammanfattas.

Flertalet studier är av tvärsnittskaraktär, och tabellen ger inga entydiga resultat. Tidigare översikter har konstaterat att det inte finns några säkra effekter av arbetslöshet på somatisk eller psykosomatisk hälsa (Hammarström 1986). Senare forskning har påvisat effekter på fysisk hälsa, särskilt bland unga kvinnor (Hammarström o.a. 1988, Hammarström 1995). I dessa studier rapporterades många olika somatiska och psykosomatiska symtom. Unga män råkade ut för fler olycksfall och besvär relaterade till försämrade matvanor och ökad alkoholkonsumtion såsom halsbränna och magså̀r. Arbetslösa unga kvinnor beskrev flera olika symptom såsom nässelutslag, förkylning, ryggvärk, huvudvärk och viktuppgång. Få studier har undersökt kliniska tecken på ohälsa. Blodtryck har studerats varvid en liten men signifikant ökning av det systoliska blodtrycket kunde konstateras bland unga män (Hammarström 1994).

Huvudparten av all forskning om arbetslöshetens effekter har ägnats åt att studera effekter på psykisk hälsa. Det visar sig finnas ett konstant samband mellan arbetslöshet och lättare psykiska problem (Warr 1987, Kieselbach 1988, Winefield 1995). Försämrad psykisk hälsa är påvisad bland såväl vuxna som ungdomar, bland kvinnor och män, i olika delar av världen samt bland människor med olika social och etnisk bakgrund. Negativa konsekvenser har påvisats i bl.a. följande avseenden (Warr 1987): lycka, livstillfredställelse, självförtroende, allmänt olycklig, oro och nedstämdhet. Tabell 3, nästa sida, sammanfattar result från olika studier. Tabellen stärker bilden av att arbetslöshet medför psykisk ohälsa.

\begin{tabular}{|c|c|c|c|}
\hline \multicolumn{4}{|c|}{ Sammanfattning av artiklar om ungdomsarbetslöshet och kroppslig ohälsa } \\
\hline rfattare & Publ.år & Design* & Resultat \\
\hline acPherson \&Wayne & 1983 & $T$ & $\begin{array}{l}\text { Inget samband mellan arbetslöshetens längd och } \\
\text { kroppslig hälsa }\end{array}$ \\
\hline kson \&Warr & 1984 & $\mathrm{~T}$ & $\begin{array}{l}\text { Inga samband mellan arbetslöshetens längd och } \\
\text { kroppslig ohälsa }\end{array}$ \\
\hline Winefield et al. & 1987 & T & $\begin{array}{l}\text { Förändringar } \mathrm{i} \text { arbetssituationen är inte relate- } \\
\text { rade till förändringar i hälsotillstånd }\end{array}$ \\
\hline Hammarström et.al. & $1988-95$ & $L$ & $\begin{array}{l}\text { Arbetslöshet medför negativa effekter på } \\
\text { kroppslig hälsa bland unga kvinnor samt ökad risk } \\
\text { för olycksfall bland unga män }\end{array}$ \\
\hline Robinson \& Duffy & 1989 & $T$ & $\begin{array}{l}\text { Arbetslöshet bland män är förenat med ölycksfall } \\
\text { och skador }\end{array}$ \\
\hline epherd et al. & 1990 & $\mathrm{~T}$ & Inget samband mellan arbetslöshet och skador \\
\hline ausen & 1991 & L & $\begin{array}{l}\text { Positivt samband mellan arbetslöshet och } \\
\text { kroppslighälsa }\end{array}$ \\
\hline
\end{tabular}

Hammarström - Arbetslöshetens konsekvenser bland ungdomar 


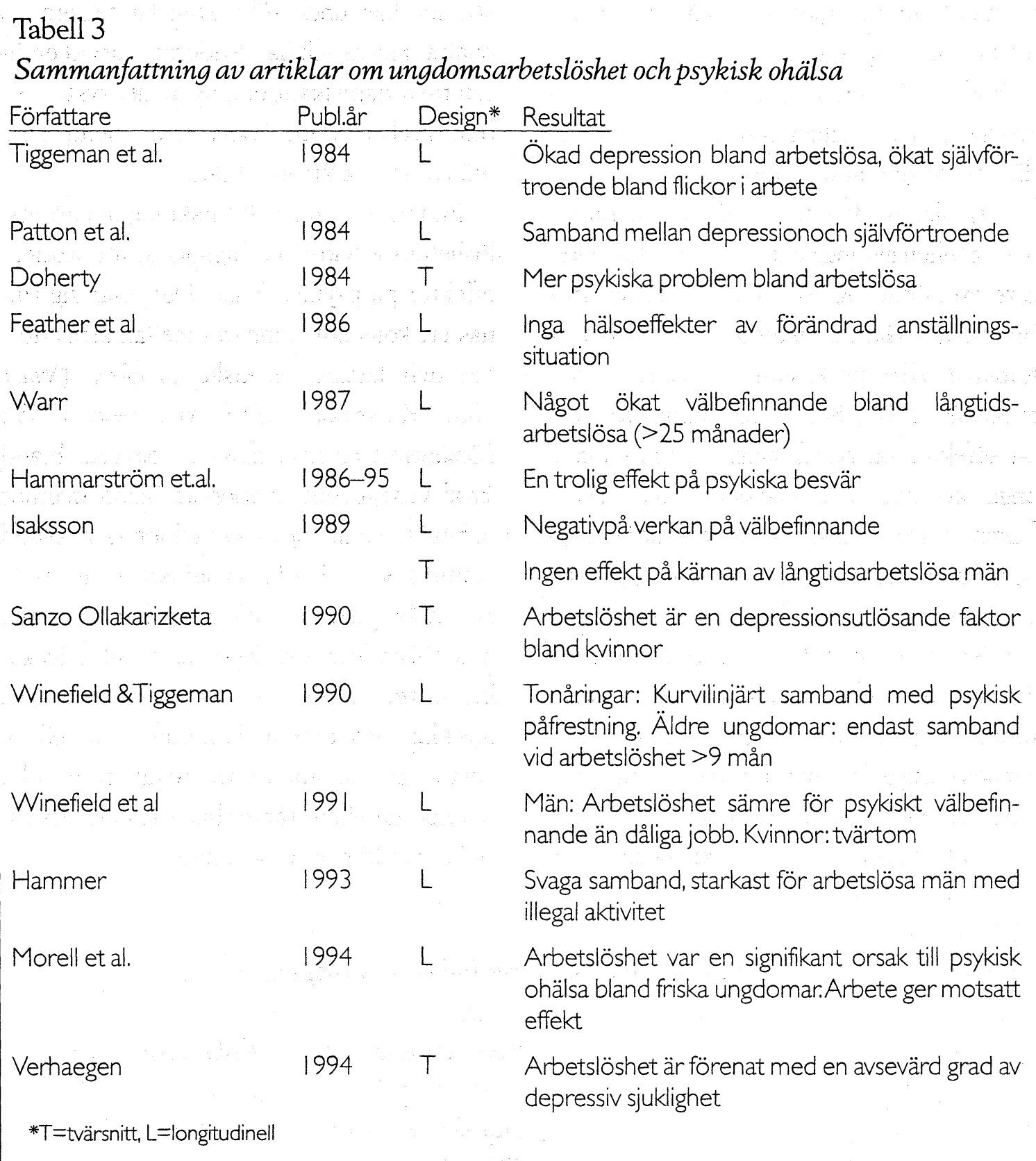

Betydelsen av arbetslöshetens längd för välbefinnandet har inte studerats tillräckligt. En del studier pekar mot något förbättrad hälsa vid långtidsarbetslöshet (Warr, Jackson 1987), medan andra pekar mot oförändrat eller minskat välbefinnande (Jackson, Warr 1984). Dosresponssamband har påvisats för såväl nervösa som depressiva besvär, vilket innebär att ju längre tid som en person går arbetslös desto högre är risken för att hon eller han får mer psykiska besvär (Hammarström 1995).

Inom arbetslöshetsforskningen används sällan kvalitativa metoder, vilket innebär en brist på kunskap om djupare mekanismer, medierande faktorer och förklarande teorier. Intervjuer pekar på tydliga samband mellan arbetslöshet och psykiska besvär, 
som bland annat medieras via bristande kontroll över den egna situationen samt en stressig tillvaro (Hammarström 1995). Sambandet är tydligast för kvinnor utan gymnasiekompetens.

\section{Sjukvårdsutnyttjande}

Som en konsekvens av ökad ohälsa vid arbetslöshet kan sjukvårdsutnyttjandet förväntas stiga. En omfattande studie av vuxna män i England visar att antalet läkarkonsultationer totalt sett fördubblas bland män som har varit arbetslösa under mer än fem år. Sambanden beror inte på en selektion till arbetslöshet bland människor med långvariga sjukdomar. Istället förefaller det att finnas ett direkt orsakssamband mellan den ökande arbetslösheten och antalet läkarbesök (Yuen, Balarajan 1989). I en annan studie från Storbritannien visade det sig att i områden med hög arbetslöshet samvarierade arbetslösheten med receptför-skrivningen av läkemedel. Sambanden är så starka att utifrån arbetslöshetsnivåerna i samhället kan läkemedelsförskrivningen inom området förutsägas (Pringle, Morton-Jones 1994).

\section{Mortalitet}

Kan arbetslöshet leda till döden? "Arbetslöshet ökar risken att man dör under en 10årsperiod med en tredjedel och för dem i medelåldern fördubblas risken«skrev redaktören för den ansedda tidskriften British Medical Journal.

Att folk dog under 30-talets depression på grund av fattigdom förvånar inte, men sker detta även i dagens samhälle? Och om så är fallet är det väl äldre människor som drabbas, inte ungdomar?

I en 10-årig dansk uppföljande studie, omfattande miljontals personer, finns tydliga samband mellan arbetslöshet och överdödlighet (Iversen o.a. 1987). Dödligheten bland arbetslösa jämfört med ickearbetslösa ökade med mellan 40 och 50 procent under en tio års period bland såväl kvinnor som män $i$ alla åldrar. Skillnaderna mellan arbetslösa och ickearbetslösa var till och med högst $\mathrm{i}$ unga år. Överdödligheten visade sig bero på en generell ökning i alla diagnosgrupper, med en viss övervikt för olycksfall och självmord. Överdödligheten kvarstår sedan hänsyn tagits till yrke, civilstånd, geografisk ort och bostadsstandard.

Andra studier har visat liknande resultat, vilket framgår av tabell 4 , nästa sida.

Forskarna har kunnat konstatera att överdödligheten inte bara beror på att de sjukaste blir arbetslösa, utan att arbetslösheten $i$ sig ökar risken för förtidig död högst avsevärt. Arbetslöshet kan därför sägas vara ett direkt hot mot folkhälsan.

\section{Sociala konsekvenser}

De sociala konsekvenserna av arbetslöshet kan i detta sammanhang endast beröras kortfattat. Ökad alienation har visats vara en effekt av arbetslöshet, snarare än en orsak till den (Winefield o.a. 1991). Brist på finansiella resurser förvärrar ofta alienationen, genom att utesluta ungdomar från fritidsaktiviter (Hendry, Raymond 1986). Betydelsen av ekonomiska svårigheter vid arbetslöshet tas upp i en annan artikel i detta nummer av tidskriften.

Det antas allmänt att arbetslöshet orsa- 


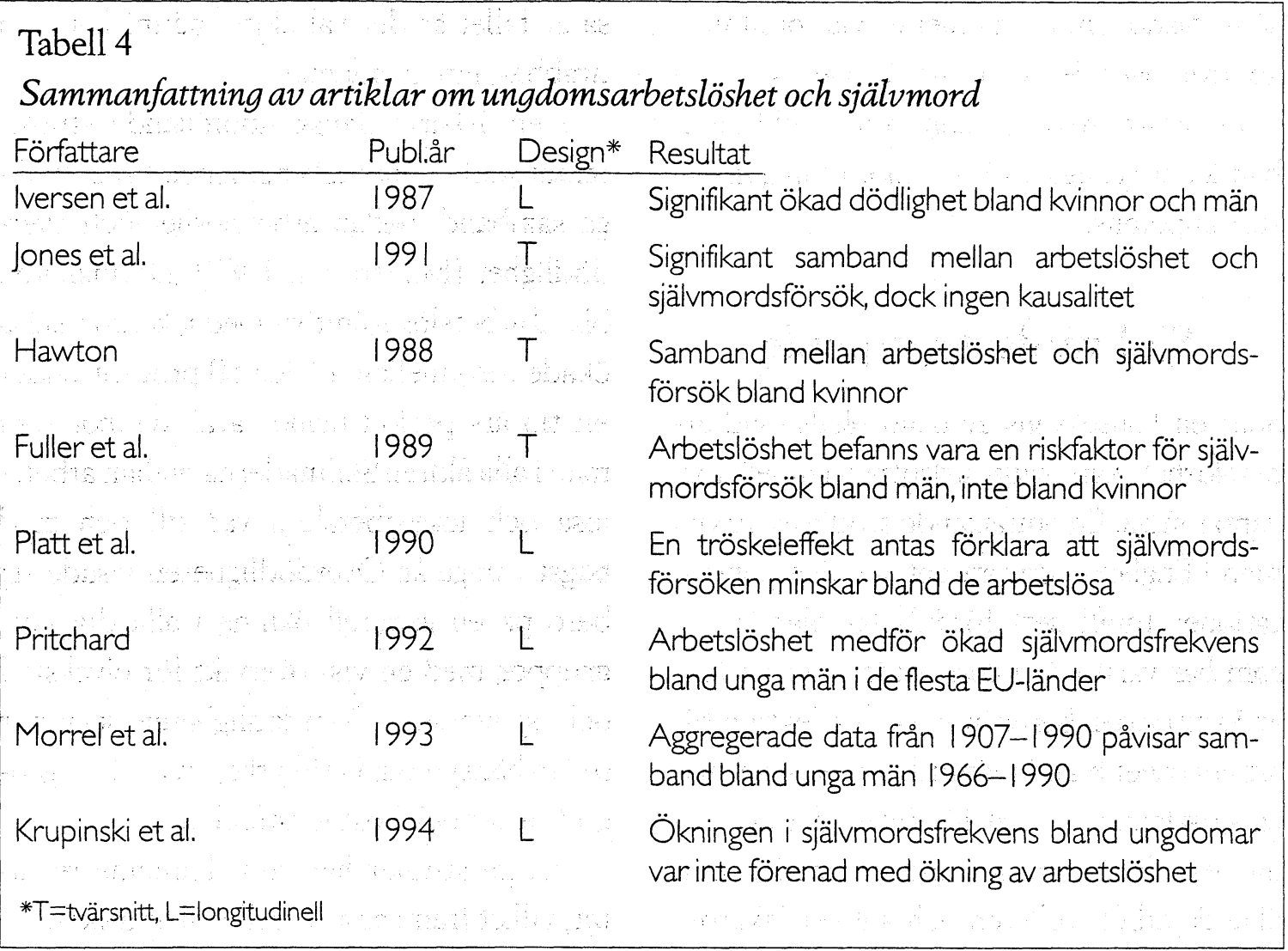

kar ökad kriminalitet samt ökat asocialt beteende (Thornberry, Christenson 1984), fast det saknas forskning inom området. En studie påvisar ökad kriminalitet bland unga män (Hammarström 1995).

\section{Utslagning}

I en femårsuppföljning av elever från årskurs nio konstateras att tidig arbetslöshet efter grundskolan är förenad med hög risk för framtida arbetslöshet bland 21-åringar, särskilt bland unga män. Risken för framtida arbetslöshet bland tidigt arbetslösa ungdomar är 2,4 gånger högre bland unga män och 1,8 gånger högre bland unga kvinnor, jämfört med dem som studerar, arbetar eller befinner sig i arbetsmarknadspolitiska åtgärder (Hammarström 1995). De unga kvinnora klarar sig således bättre ur arbetslöshe- ten jämfört med de unga männen, trots större svårigheter på arbetsmarknaden. Några tänkbara förklaringar till detta kan vara att de unga kvinnorna är mer aktivt arbetssökande; de har högre arbetsengagemang, är mer villiga att ta vilket jobb som helst, flyttar i större utsträckning till områden där de lättare kan få jobb samt vidareutbildar sig oftare. Med kvalitativa metoder påvisas dessutom att relationsinriktning och ansvarstagande medför att kvinnor i högre utsträckning bryter sig ur arbetslöshetens onda cirklar (Hammarström 1995).

I diskussioner kring utslagning av ungdomar är det också viktigt att ha ett förebyggande perspektiv. Arbetslöshet kan medföra att ungdomar halkar allt längre ner på samhällsstegen under resten av deras liv, men detta behöver inte oundvikligen bli konsekvensen. Tvärtom beror i själva verket 
långtidseffekterna för de arbetslösa på arbetsmarknadspolitiken (Travers 1985). Ett exempel kan ges från Australien under 1930-talet. Arbetslöshetens förödande effekter resulterade i att statsmakterna tog ansvar för att upprätthålla full sysselsättning, vilket blev hörnsten i australiensk socioekonomisk politik under mer än 35 år.

\section{Medierandefaktorer}

Ett antal studier har försökt belysa frågor som handlar om vilka medierande faktorer som kan tänkas antingen förmedla hälsoeffekterna av arbetslöshet eller som kan skydda en arbetsłös person från ohälsa. Några av studierna sammanfattas i tabell 5 .

Ett flertal studier har påvisat hur socialt stöd från familjen, vänner och samhällsinrättningar kan minska de negativa effekterna av arbetslöshet. Att vara arbetslös i områden med hög arbetslöshet kan innebära ökad tillgång till socialt stöd samt minskad risk för att omgivningen ska skuldbelägga den arbetslösa. Efter kontroll för sjukdomsframkallande faktorer har ocksà hälsotill-

\begin{tabular}{|c|c|c|c|}
\hline Medierande faktor & Författare & $\AA ̊ A r$ & Samband \\
\hline Social stöd & $\begin{array}{l}\text { Clark \& Clissold } \\
\text { Jackson \&Warr } \\
\text { Ullah et al. } \\
\text { Finlay-Jones \& Eckhardt } \\
\text { McPherson \&Wayne } \\
\text { Winefield et al. } \\
\text { Hammer }\end{array}$ & $\begin{array}{l}1982 \\
1984 \\
1985 \\
1984 \\
1983 \\
1990 \\
1993\end{array}$ & $\begin{array}{l}+ \\
+ \\
+ \\
+ \\
- \\
+ \\
+\end{array}$ \\
\hline Arbetsattityder & $\begin{array}{l}\text { Feather } \\
\text { Ullah et al } \\
\text { Stafford et al } \\
\text { Stafford \& Jackson } \\
\text { MacPherson \&Wayne } \\
\text { Jackson et al } \\
\text { Warr \& Jackson } \\
\text { Winefield et al }\end{array}$ & $\begin{array}{l}1983 \\
1985 \\
1980 \\
1980 \\
1983 \\
1983 \\
1987 \\
1987\end{array}$ & $\begin{array}{l}+ \\
+ \\
+ \\
- \\
- \\
+ \\
+ \\
-\end{array}$ \\
\hline Syn på arbetslshetens orsaker & $\begin{array}{l}\text { Patton \& Noller } \\
\text { Feather \& O'brien } \\
\text { Feather } \\
\text { Tiggeman \& Winefield } \\
\text { Gurney } \\
\text { Donovan \& Oddy }\end{array}$ & $\begin{array}{l}1984 \\
1986 \\
1982 \\
1984 \\
1980 \\
1982\end{array}$ & $\begin{array}{l}+ \\
+ \\
- \\
- \\
- \\
-\end{array}$ \\
\hline Ekonomi & $\begin{array}{l}\text { Finlay-Jones \& Eckhardt } \\
\text { Jackson \& Warr } \\
\text { Broombalt \&WVinefield } \\
\text { Rosvold \& Hammer }\end{array}$ & $\begin{array}{l}1984 \\
1984 \\
1990 \\
1991\end{array}$ & $\begin{array}{l}+ \\
+ \\
+ \\
+\end{array}$ \\
\hline Aktiv jobbsökning & Kaul \& Kvande & 1991 & + \\
\hline
\end{tabular}




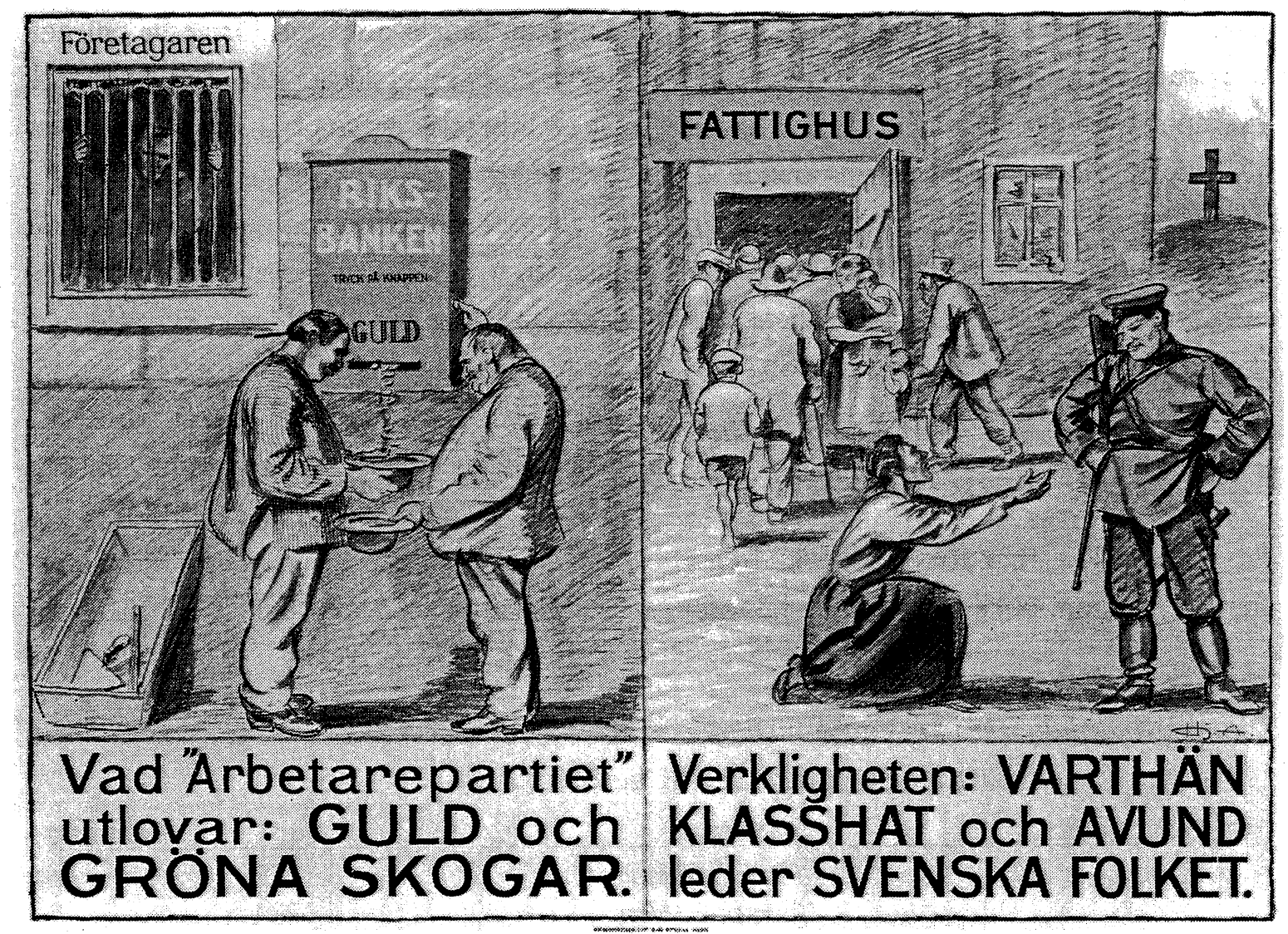

Socialvetenskaplig tidskrift nr 1-2 •96 
ståndet befunnits vara bättre i områden med mycket hög arbetslöshet (Clark, Clissold 1982). Detta stöder hypotesen att hög arbetslöshet medför ökad motståndskraft som är välgörande för de arbetslösas psykiska hälsa.

En annan ofta studerad faktor som kan påverka konsekvenserna av arbetslöshet är olika attityder till arbete. De negativa effekterna av högt arbetsengagemang påvisades tidigt av engelska forskare (Stafford o.a. 1980), som observerade att ungdomar med hög arbetsorientering upplevde större förlust av självförtroende vid arbetslöshet. Men högt arbetsengagemang kan också bli en stark drivkraft att ta sig ur arbetslösheten.

I flera kulturer har arbetslösa ungdomar befunnits ha lägst grad av arbetsengagemang. I en longituinell studie påvisades att minskat arbetsengagemang var en konsekvens av snarare än en orsak till arbetslöshet (Hammarström 1995). Arbetsvärderingar kan sålunda betraktas som såväl ett resultat av arbetslöshet och som medierande faktor vid arbetslöshet. Som medierande faktor kan arbetsvärderingar leda till såväl ökad som minskad risk för utslagning.

Synen på vad arbetslöshet beror på kan påverka hälsotillståndet som arbetslös. Personer med intern kontroll-lokus kan förväntas må bättre jämfört med de som förlägger skulden på samhället, eftersom de upplever att de själva kan kontrollera sin situation. Empirisk forskning har inte lyckats visa att det spelar någon roll om individen är orienterad mot extern eller intern kontroll-lokus.

I en tidig översikt dras slutsatsen att bristen på bra studier inom området är orsaken till att det saknas replicerbara resultat och teorier om medierande faktorer (Donovan, Oddy 1982). Bilden har därefter knappast klarnat. En studie visar att arbetslösa ungdomar har mest extern kontroll (Patton, Noller 1984). En annan översikt drar slutsatsen att kvinnor och ungdomar från arbetarklassen är mer extern orienterade än män (Furnham 1985). Andra studier pekar emellertid åt andra riktningar (Tiggemann, Winefield 1984).

Ett stort antal studier har påvisat att ekonomisk trygghet är av central betydelse för att människor på ett bättre sätt ska kunna hantera den stress som arbetslösheten medför. Vad aktiv jobbsökning betyder för att minska arbetslöshetens följdverkningar har nyligen uppmärksammats i en studie (Kaul, Kvande 1991).

I longitudinell forskning har en teoretisk modell verifierats, i vilken brist på kontroll är av central betydelse (Hammarström o.a. 1988).

\section{Slutsats}

Sedan början av 1980-talet har ett ökande antal artiklar publicerats om framförallt de individuella konsekvenserna av arbetslöshet. Men det är alltjämt ont om studier av god kvalitet som fokuserar ungdomsarbetslöshetens hälsokonsekvenser. De fåtal studier som finns på grupp- och samhällsnivå indikerar ökad risk för allvarliga följdverkningar av ungdomsarbetslöshet, exempelvis ökad förekomst av sexualiserat våld.

På en individuell nivå pekar forskningen mot konsistenta samband mellan arbetslöshet och lättare psykiska besvär. Få studier har på ett tillfredställande sätt studerat ungdomsarbetslöshetens effekter på 
kroppslig hälsa samt hälsovanor. Högt bortfall i kombination med problematisk design försvårar möjligheterna att dra slutsatser från många studier. Det behövs således fler studier av god kvalitet. De tillförlitliga studier som finns pekar mot ökad kroppslig ohälsa samt försämrade hälsovanor som en följd av arbetslöshet. Arbetslöshet medför dessutom ökad risk för sociala konsekvenser i form av bland annat ökad risk för alienation, utslagning samt kriminalitet. Dessa studier visar också att sambanden mellan arbetslöshet och ohälsa beror på såväl selektion som exposition. Forskningen visar således att arbetslöshet kan ha en kausal effekt på hälsa och hälsovanor.
Dessa viktiga resultat borde utgöra startskott för kraftfulla aktioner mot ungdomsarbetslöshet, i ettfolkhälsoförebyggande syfte.

Forskningen behöver nu inriktas mot mer kvalitativa metoder som utifrån ett genusperspektiv söker efter djupare mekanismer, medierande faktorer samt förklaringsmodeller om orsakerna till den ojämlikt fördelade hälsan, i vilken arbetslöshet har visat sig vara en viktig faktor.

\section{Acknowledgement: Socialvetenskapliga} forskningsrådet och Folkhälsoinstitutet har finansierat min forskning.

\section{Referenser}

Abramson LY, Seligman ME, Teasdale JD (1978). Learned helplessness in humans: Critique and reformulation. Journal of Abnormal Psychology 87, 49-74, 1978.

Arnetz BB, Wasserman J, Petrini B, Brenner SO, Levi L, Eneroth P, Salovaara H, Hjelm R, Salovaara L, Theorell T, Petterson IL (1987). Immune function in unemployed women. Psychosom Med, 149, 3-12.

Berggren A. Om medicinsk kvinnoforskning, hälsa och genus. FRN. Stencil 1995.

Brenner MH (1980). Estimating the social costs of youth unemployment problems 1947-1976. The Vice President's task force on youth unemployment. Center for Public Service, Brandeis University, Waltham.

Brenner MH, Mooney A (1983). Unemployment and health in the context of economic change. Soc Sci Med $17,1125-1138$.

Broomhall HS, Winefield AH (1990). A comparison of the affective well-being of young and middle-aged men, matched for length of unemployment. British Journal of Medical Psychology, 63, 345-354.

Clark AW, Clissold MP (1982). Correlates of adaptation among unemployed and employed young men. Psychological reports 50, 887-893.

Claussen, B. (1994). Deprived of work and health? A two year follow up of long term unemployed from Grenland, Norway 1988-90. Oslo: National Institute of Public Health, Unit for Health Services Research and University of Oslo. [Thesis].

Cobb S, Kasl SV (1977). Termination: The consequences of job loss. Cincinnati: US Department of Health, Education and Welfare (DHEW/NIOSH Publ. No. 77-224).

Davies K, Esseveld J (1988). Att hoppa hage i den svenska arbetsmarknaden: Raben och Sjögren. Stockholm.

Doherty J, Davies C (1984). The psychological effects of unemployment on a group pf adolescents. Educational review 36,217-228.

Donovan, A. Oddy M(1982). Psychological aspects of unemployment: an investigation into the emotional and social adjustment of school leavers. Journal of Adolescence 5, 15-30. 
Eiser C(1985). The psychology of childhood illness. New York: Springer.

Feather NT (1982). Unemployment and its psychological correlates: a study of depressive symptoms, selfesteem, protestant ehtic values, attributional style and apathy. Australian Journal of Psychology 34(3):309-323.

Feather NT (1983). Causal attributations and beliefs about work and unemployemnt among adolescents in state and independent secondary schools. Australian Journal of Psychology, 35, 211-232.

Feather NT, O'Brien GE (1986). A longitudinal analysis of the effects of different patterns of employment and unemployment on school-leavers. British Journal of Psychology 77, 459-479.

Finlay-Jones R, Eckhardt B (1984). Psychiatric disorder among the young unempployed. Australian and New Zealand Journal of Psychiatry 18, 135-143.

Forcier MW (1988). Unemployment and alcohol abuse: A review, Journal of Occupational Medicine, 30, 246-251.

Fuller GN, Rea AJ, Payne JF, Lant AF (1989). Parasuicide in central London 1984-1988. Journal of the Royal Society of Medicine 82, 653-656.

Furnham A (1985). Youth unemployment: a review of the literature. Journal of Adolescence, 8,109-124.

Gupta RK, Srivastava AK (1987). Study of fatal burns cases in Kanpur (India). Forensic Sci Int,37, 81-9.

Gurney RM (1980). Leaving school, facing unemployment and making attributions about causes of unemployment. Journal of Vocational Behavior 18, 79-91.

Hammarström Anne (1986). Ungdomsarbetslöshet och ohälsa. Resultat från en två-årsuppföljning. Karolinska Institutet, Statens Institut för Psykosocial Miljömedicin och Socialmedicinska institutionen »Kronan". Akademisk avhandling. Stockholm och Sundbyberg.

Hammarström A, Janlert U, Theorell T(1988). Youth unemployment and ill-health: results from a 2-year follow-up study. Soc Sci Med,26, 1025-33.

Hammarström A (1994). Health consequences of youth unemployment - review from a gender perspective. Soc Sci Med,38(5),699-709.

Hammarström A, Janlert U(1994). Unemployment and change of tobacco habits. A study from 16 to 21 years of age. Addict, 89,1691-1696.

Hammarström A (1994). Health consequences of youth unemployment. Public Health,108,403-412.

Hammarström A (1995). Arbetslöshet och ohälsa- om ungdomars livsvillkor. Lund: Studentlitteratur.

Hammer T (1991). Risk factors related to use of alcohol and cannabis in the general population: a longitudinal study of the influence of employment, unemployment and mental health. Thesis. Dep of Behavioural Science in Medicine, Oslo.

Hammer T (1993). Unemployment and mental health among young people: a longitudinal study. J of Adolescence 16, 407-420.

Harding S. The science question in feminism. Ithaca, N.Y.: Cornell university press 1986.

Hawton K, Fagg J, McKeown SP (1989). Alcoholism, alcohol and attempted suicide. Alcohol \& Alcoholism,24,3-9.

Hendry LB, Raymond M (1986). Psychological/sociological aspects of youth unemployment: An interpretative theoretical model. Journal of Adolescence, 9, 355-366.

Isaksson K (1989). Unemployment, mental health and the psychological functions of work in male welfare clients in Stockholm. Scand J Soc Med.17, 165-169, 1989.

Iversen L, Andersen O, Andersen PK, Christoffersen K, Keiding N. Unemployment and mortality in Denmark, 1970-80. Brit. Med. J. 1987;295:879-884.

Jackson PR, Warr PB (1984). Unemployment and psychological ill-health: the moderating role of duration and age. Psychological Medicine, 14,605-14.

Jackson PR, Stafford EM, Banks MH and Warr PB (1983). Unemployment and psychosocial stress in young people. The moderating role of employment commitment. Journal of Applied Psychology, 68, 525-535.

Hammarström - Arbetslöshetens konsekvenser bland ungdomar 
Jahoda M (1979). The impact of unemployment in the 1930s and the 1970s. Bulletin of the British Psychology Society 32, 309-314.

Jahoda M. Employment and unemployment. A Socialpsychological analysis, Cambridge University Press. Cambridge 1982.

Janlert U (1991). Work deprivation and health. Consequences of job loss and unemployment. Luleå/Sundbyberg: Karolinska Institute.

Janlert U, Hammarström A (1992). Alcohol consumption among unemployed youths. Results from a prospective study. British Journal of Addiction, 87, 703-14.

Jones SC, Forster DP,Hassanyeh F (1991). The role of unemployment in parasuicide. Psychological Medicine 21, 169-176.

Kagan A, Levi L (1975). Health and environment-psychosocial stimuli. A review. In Levi L(Ed). Society stress and disease. Vol II. London: Oxford University Press 241-260.

Kandel DB, Davies M, Karus D \& Yamaguchi K(1986). The consequences in young adulthood of adolescent drug involvement, Archives of General Psychiatry, 43, 746-754.

Karasek R. Theorell T(1990). Healthy Work. New York: Basic Books.

Kaul $\mathrm{H}$, Kvande E(1991). Mestring av arbeidsledighet. Tidskrift for samfunnsforskning,32,3-21.

Kieselbach T (1988). Youth unemployment and health effects. The International Journal of Psychiatry32, 83-96.

Krupinski J, Tiller J W, Burrows GD, Hallenstein H(1994). Youth suicide in Victoria: a retrospective study. Med J Aust, 160, 113-116.

Layne N, \& Whitehead PC (1985). Employment, marital status and alcohol consumption of young Canadian men, Journal of Studies on Alcohol 46, 538-540.

Leeflang RLI, Klein-Hesselink DJ, Spruit IP. Health effects of unemployment -II. Men and women. Soc Sci Med 1992;34(4):351-363.

McPherson A, Wayne H(1983). Psychiatric impairment, physical health and work values among unemployed and apprenticed young men. Australian and New Zealand Journal of Psychiatry 17, 335-40.

Miles I (1983). Work, wellbeing and unemployment: a study of men in Brighton. In New Technology and future of Work and Skills. London 1983, 93-102.

Morrell S, Taylor R, Quine S, Kerr C, Western J (1994). A cohort study of unemployment as a cause of psychological disturbance in Australian youth Soc. Sci. Med. 38 1553-1564

Morris JK, Cook DG, Shaper AG (1992). Non-employment and changes in smoking, drinking, and body weight. BMJ,304,536-41.

Moser KA, Fox AJ, Goldblatt PO, Jones DR (1986). Stress and heart disease: evidence of associations between unemployment and heart disease from the OPCS longitudinal study. Postgrad Med J,62, 797-9.

OECD (1994). Employment Outlook. Paris: OECD.

Ovesen E(1978). Arbetslöshetens psykiska följdverkningar. Raben \& Sjögren. Stockholm.

Patton W, Noller P (1984). Unemployment and youth: a longitudinal study. Australian Journal of Psycholo gy, 36,399-413.

Peck DF \& Plant MA (1986). Unemployment and illegal drug use: concordant evidence from a prospective study and national trends, British Medical Journal 293, 929-932.

Penkower L, Bromet EJ, Dew MA (1988). Husbands' layoff and wives' mental health. A prospective analysis. Arch Gen Psychiatry 45, 994-1000.

Platt S, Kreitman N (1990). Long term trends in parasuicide and unemployment in Edinburgh. Social Psychiatry and Psychiatric Epidemiology 25, 56-61.

Power C, \& Estaugh V (1990). Employment and drinking in early adulthood: a longitudinal perspective, British Journal of Addiction 85, 487-494. 
Preventing Tobacco Use Among Young People: A Report of the Surgeno General. Atlanta, Georgia: U.S. Department of Health and Human Services, 1994.

Pringle M, Morton-Jones A (1994). Using unemployment rates to predict prescribing trends in England. Br. J. Gen. Pract. 44, 53-56.

Pritchard C (1992). Is there a link between suicide in young men and unemployment? A comparison of the UK with other European Community Countries, Br J Psychiatry160, 750-756.

Roberts K. Duggan J and Noble M (1982). Out of school youth in high unemployment areas: an empirical investigation. British Journal of Guidance and counseling,10, 1-72.

Robinson AD, Duffy JC (1989). A comparison of self-injury and self-poisoning from the Regional Poisoning Treatment Centre, Edingburgh. Acta Psychiatr Scand 80, 272-9.

Rosenthal JA (1988). Patterns of reported child abuse and neglect. Child Abuse Negl,12, 263-71.

Rosvold EO, Hammer T (1991). En longitudinell studie av arbeidsloshet og ekonomisk mestring relaterat til mental helse. Tidskrift for samfunnsforskning, 32, 121-142.

Russel D (1986). The secret trauma. New York: Basic Book Inc Publishers.

Rutter M, Sandberg S (1987). Epidemiology of child psychiatry disorder: Methodological issues and some substantive findings. In: Chess S \& Thomas A(Eds): Annual progress in child psychiatry and child development. New York: Bonner Mazel.

Sanzo Ollakaritzketa JM(1990). Prevalence of depressive symptoms in adolescents and young adults. Gac Sanit 4, 55-9, [in Spanish].

Seligman MEP (1975). Helplessness. San Fransisco: Freeman.

Shepherd JP, Robinson L, Levers BG (1990). Roots of urban violence. Injury 21,139-41.

Stafford EM, Jackson PR and Banks MH (1980). Employment, work involvement and mental health in less qualified young people. Journal of Occupational Psychology.53, 291-304.

Stafford E, Jackson PR (1980). Work involvement in school leavers in an area of high unemployment. The Vocational Aspect of Education 32, 1-3.

Starrin B, Lundberg B, Wall H, Angelöv B (1985). Arbetslöshet, övertidsarbete och intensitet i arbetet. Forskningsrapport nr 1. Värmlands läns landsting: Karlstad, 1985.

Tiggemann M, Winefield AH (1984). The effects of unemployment on the mood, self-esteem, locus of control and depressive affect of school-leavers. Journal of Occupational Psychology, 57, 33-42.

Thornberry TP, Christenson RL (1984). Unemployment and criminal involvement: an investigation of reciprocal causal structures. American Socialogical Review. 49, 398-411.

Travers P (1985). Unemployment and the downward trail. Austr. Journal of Social Issues 20, $12-22$.

Ullah P, Banks MH, Warr P (1985). Social support, social pressures and psychological distress during unemployment. Psychological Medicine 5, 83-295.

Waldron I, Lye D (1989). Employment, unemployment, occupation, and smoking. American Journal of Preventive Medicine, 5, 142-149.

Warr P, Jackson P (1987). Adapting to the unemployed role: a longitudinal investigation. Soc Sci Med 25,(11), 1219-24.

Warr P (1987). Work, unemployment and mental health. Oxford:Clarendon Press.

Verhaegen L, Deykin EY, Sand E (1994). Depressive symptoms and employment status among Belgian adolescents. Rev Epidemiol Sante Publique, 42, 119-127.

Winefield HR, Winefield AH, Tiggemann M, Smith S (1987). Unemployment, drug use and health in late adolescence. Psychother. psychosom. 47, 204-210.

Winefield HR, Tiggemann M, Smith S (1987). Unemployment, attributional style and psychological wellbeing. Personality and Individual Differences, 8, 659-666.

Winefield AH, Tiggemann M, Winefield HR (1990). Factors moderating the psychological impact of unemployment at different ages. Personality and Individual Differences, 11, 45-52. 
Winefield AH, Tiggemann M (1990). Length of unemployment and psychological distress: Longitudinal and cross-sectional data. Soc Sci Med31, 461-465.

Winefield AH et al (1991). Social alienation and employment status in young adults. Journal of organizationalbehavior. 12, 145-154.

Winefield AH(1995). Unemployment: its psychological costs. Ed Cooper CL, Robertson IT. International Review of Industrial and Organizational Psychology. Vol 10, chapter 5, 169-212.

Yuen P, Balarajan R (1989). Unemployment and patterns of consultation with the general practitioner. BMJ May 6, 298, (6682), 1212-4.

\section{Summary}

\section{Health consequences of unemployment among young people}

Current research is classified into different theoretical approaches, mainly economic deprivation theories, stress-related theories, gender theories and different psychological and sociological theories. The correlations between unemployment and ill-health are explained as a result of both selection and exposure. The societal consequences of youth unemployment have been studied in aggregate studies. The familial consequences is a neglected area, but there is evidence of increased illness as well as battering of wives and children. Almost all research has been focused on the individual and mainly on the psychological consequences. Consistent relationships are found between unemployment and minor psychological disorders. Few studies have included somatic health but the results indicate increased physiological illness, especially among unemployed girls. Increased health care consumption has been documented. There are evidence that unemployment is a risk indicator for both increasing alcohol con- sumption, particularly in young men. Unemployment is also associated with increased tobacco consumption, increased use of illicit drugs as well as deteriorated health behaviour is the unemployed. The mortality rate is significantly higher among unemployed young men and women, especially in suicides and accidents. Social consequences include increased risk of alienation, lack of financial resources, criminality and future exclusion from the labour market. As mediating factors social support, high employment rate, negative attitudes towards work and high possibility of control have been documented to have a protective effect on health. Research should now be directed towards more qualitative methods, based on theoretical models, in order to search for deeper mechanisms, mediating factors and explanatory theories of the unevenly distributed health in society, in which unemployment has been proved to be one important factor. 